\title{
Big data e levantamento de informações sobre o manejo e a produtividade na cultura do tabaco na Região dos Campos Gerais - PR
}

\author{
Big data and collection of information about the management and productivity in tobacco culture \\ in the Campos Gerais Region - PR \\ Grandes datos y recopilación de información sobre la gestión y productividad en el cultura del \\ tabaco en la Región Campos Gerais - PR
}

Recebido: 20/05/2021 | Revisado: 28/05/2021 | Aceito: 07/06/2021 | Publicado: 21/06/2021

\author{
Leticia Horst \\ ORCID: https://orcid.org/0000-0003-0049-5309 \\ Centro Universitário Cesumar, Brasil \\ E-mail: leticiahorst8@gmail.com \\ Isabela Leticia Pessenti \\ ORCID: https://orcid.org/0000-0002-5176-3134 \\ Centro Universitário Cesumar, Brasil \\ E-mail: isabela.pessenti@unicesumar.edu.br
}

\begin{abstract}
Resumo
O tabaco (Nicotina tabacum) é uma cultura que está presente principalmente na Região sul do país, assim podendo ser uma boa alternativa para pequenos produtores na zona rural. Com isto, a realização de um estudo através de questionários compartilhados por trinta produtores da Região dos Campos Gerais, no estado do Paraná, puderam apresentar individualmente, através de questões descritivas e de múltipla escolha, apresentar sua forma de cultivo, apontar sugestões e também suas principais dificuldades, como por exemplo na adubação do solo. Assim, gerando a possibilidade de criar formas de levar informações que sejam relevantes aos produtores e que possam de alguma maneira alavancar sua produção, garantindo qualidade de serviço e também de produto.
\end{abstract}

Palavras-chave: Produção de tabaco; Pequenos produtores rurais; Questionário.

\begin{abstract}
Tobacco (Nicotina tabacum) is a crop that is present mainly in the southern region of the country, so it can be a good alternative for small producers in the countryside. With this, the accomplishment of a study through questionnaires shared by thirty producers of the Region of Campos Gerais, in the state of Paraná, they could present individually, through descriptive and multiple choice questions, to present their form of cultivation, to point out suggestions and also their main difficulties, such as fertilizing the soil. Thus, generating the possibility of creating ways to take information that is relevant to producers and that can somehow leverage their production, ensuring quality of service and also of product.
\end{abstract}

Keywords: Tobacco production; Small rural producers; Questionnaire.

\section{Resumen}

El tabaco (Nicotina tabacum) es un cultivo que está presente principalmente en la región sur del país, por lo que puede ser una buena alternativa para los pequeños productores del campo. Con ello, la realización de un estudio a través de cuestionarios compartidos por treinta productores de la Región de Campos Gerais, en el estado de Paraná, pudieron presentar individualmente, a través de preguntas descriptivas y de opción múltiple, presentar su forma de cultivo, señalar sugerencias y también sus principales dificultades, como la fertilización del suelo. Generando así la posibilidad de crear formas de tomar información que sea relevante para los productores y que de alguna manera pueda apalancar su producción, asegurando calidad de servicio y también de producto.

Palabras clave: Producción de tabaco; Pequeños productores rurales; Cuestionario.

\section{Introdução}

A indústria de tabaco se consolida a partir do final do século XIX com a invenção da máquina de confeccionar cigarros em 1881, sendo o setor dominado desde esse período pelas multinacionais estadunidenses e britânicas. Entre 1904 e 1947 , as indústrias de tabaco dos Estados Unidos crescem tão ou mais rapidamente que as de carros, lançando marcas populares de 
cigarros. No Brasil, o chamado "sistema integrado de produção de tabaco (SIPT)" foi criado pela British American Tobacco (BAT) em 1918, na Região Sul. A BAT é controladora acionária da Souza Cruz desde 1914, e se torna, no fim da Segunda Guerra Mundial, a maior fabricante de cigarros do mundo, expandindo-se principalmente na China (Boeira, 2006).

Segundo Afubra (2018), na década de 1940 a região Sul já alcançava a posição de maior produtora de tabaco em folha, com 52\% da produção nacional. De 1940 a 2006 a região Sul apresenta um crescimento de aproximadamente 31 vezes. Nela, destacam-se Santa Catarina e Paraná que a partir dos anos 1975 passam a ser segundo e terceiro maiores produtores, respectivamente, atrás apenas do Rio Grande do Sul, correspondendo por 96,8\% da produção nacional (Riquinho; Hennington, 2016; Rosa, 2018).

A cultura do tabaco contribui de maneira significativa para o desenvolvimento econômico e social do país. Na região Sul do Brasil, participam desse ciclo produtivo no meio rural, aproximadamente 149.350 famílias, que produzem cerca de 685.983 toneladas de tabaco, contabilizando uma receita anual bruta de aproximadamente R\$ 6,2 bilhões (Afubra, 2018). O Brasil é um mercado consolidado, um fornecedor mundial, maior exportador de tabaco e continuará sendo. Isso se deve a diversos fatores, como a competência dos produtores e o investimento em tecnologias, que é traduzido em ferramentas de eficiência produtiva nas propriedades e também nas indústrias (Salvadego, 2019).

O mercado mundial vem sofrendo rápidas mudanças diante da implementação de novas tecnologias e, a partir disso, o comportamento dos consumidores também está sendo alterado. As novidades estão em todas as áreas produtivas da cadeia econômica, inclusive no agronegócio. Por isso, o produtor rural precisa manter-se atento às tecnologias e aplicá-las no seu negócio para gerenciar a sua propriedade (Klettenberg, 2019). Segundo Afubra (2018), a produção do tabaco se concentra em 96\% no sul do país na safra de 2018/2019. Houve também mudanças em sua produção entre os anos 2009 a 2019 , sendo que a produtividade era mais baixa, com a implantação da tecnologia, houve aumento de $33 \%$ no preço por quilo e $11 \%$ na produtividade. Entre as cidades que compõem a Região dos Campos Gerais, Ipiranga e São João do Triunfo, estão entre os cinco maiores produtores de tabaco de todo o estado paranaense (Seab, 2019).

Com a demanda de novas tecnologias neste ramo, cada vez mais a produtor necessita auxílio para realização de cálculos de calagem e adubação, como por exemplo. A interpretação e raciocínio também são extremamente importantes. Mas conforme Silveira (2015), apenas $2,1 \%$ dos produtores tem o ensino médio completo, sendo a maioria de $90 \%$ dos produtores com o ensino fundamental incompleto, ou seja, que cursaram em média até o $7^{\circ}$ ano. Em relação ao ensino superior os resultados são mínimos, sendo apenas $0,3 \%$ que cursam ou tem o ensino superior incompleto (Riquinho; Hennington, 2016).

Com a consciência de tais resultados onde a produtividade está aumentando, o produto está sendo mais valorizado. Porém os produtores, em sua grande maioria, têm uma baixa escolaridade, o que dificulta a busca de informações atualizadas de confiabilidade, principalmente de artigos científicos de grande impacto. E também um local onde os produtores rurais possam esclarecer dúvidas, facilitar também a resolução de cálculos de adubação ou doses de produtos indicados para a cultura. Com a finalidade principal de melhorar as condições de trabalho no campo.

Com a coleta de informações através de questionários possibilita o acesso a resultados mais precisos e realistas. Com produtores que estão atuando na área, com diferentes visões de produção, diferentes realidades e conhecimentos. Podendo desenvolver um estudo mediante aquilo que é demandado pelo produtor e que irá realmente ser útil e interessante a ele.

Com isso o trabalho tem como objetivo geral efetuar o levantamento e coleta de informações sobre a cultura do tabaco para Região dos Campos Gerais - PR. Realizar uma análise descritiva dos dados e resumir de maneira que seja facilmente interpretada pelos produtores de tabaco, independente da sua escolaridade. Propondo a maneira mais fácil de acessar essas informações pelos produtores. 


\section{Metodologia}

Como forma de conexão com o produtor, foram elaborados quatro questionários, cada um representando uma fase de produção: Produção de mudas, plantio, cultivo e colheita. Assim possibilitando analisar e estudar cada uma das fases separadamente. Os questionários eram compostos com dez a vinte questões, sendo elas de múltipla escolha e também descritivas.

Primeiramente é realizado um estudo prévio sobre a fase que seria estudada, elaborada questões, revisadas, compartilhadas para 30 produtores da Região dos Campos Gerais. Cada questionários ficava aberto a respostas por aproximadamente duas semanas, após este período as respostas eram organizadas em uma plataforma de planilhas para melhor compreensão.

A produção do tabaco sabe-se que é ainda muito manual, que muitas vezes é passada de gerações em uma família, o que pode resultar em manejos ultrapassados, ou que nem trazem tanto resultado como o que se pode alcançar. A busca de conhecimento está crescendo, principalmente em plataformas digitais que são cada vez mais acessíveis.

\subsection{Produção de Mudas}

A fase inicial da safra consiste em produzir mudas em sistema float e após um período médio de dois meses é realizado o plantio, com o transplante de mudas já desenvolvidas e preparada para ir ao solo. Com o objetivo de adquirir uma caracterização dos produtores que estavam participando do estudo e de entender a realidade de cada um dos produtores foram elaboradas questões referentes a: composição familiar, gênero, idade, período de plantio, fonte de renda, variedade cultivada, tipo de solo, análise de solo, época de semeadura, tipo de substrato, tipo de bandeja, principais doenças e pragas, preço de compra e preço de produção de mudas.

Após o compartilhamento dos questionários com produtores da Região dos Campos Gerais, é necessário organizar os resultados, analisar e interpretar aquilo que foi coletado. Para que através disso se possa futuramente possa criar um meio de informação de qualidade, com informações que realmente o produtor necessita.

\subsection{Plantio}

Como citado anteriormente, as mudas quando desenvolvidas, atingindo um porte de aproximadamente $15 \mathrm{~cm}$, são transplantadas no solo. Elaborado um questionário, onde foram adquiridos resultados referentes a: época de plantio, quantidade de mudas/ha, quantidade de podas, forma de preparo do solo, sistema de plantio e adubação.

\subsection{Cultivo}

O terceiro questionário abordou temas referentes ao tipo de mão-de-obra utilizada nesta etapa, preço da mão-de-obra terceirizada, principais doenças e pragas e tipo de manejo delas, agrotóxicos, conhecimentos sobre a cultura e formas utilizadas para auxílio de informações sobre a produção.

\subsection{Colheita, secagem e venda}

Por fim, no último questionário foram apresentados temas relacionados à época, ponto, período, mão-de-obra referentes à colheita. Estrutura das secagens das folhas, tipo de secagem, utilização, quantidade e preço de lenha para secagem em estufas. Classificação das folhas, mão-de-obra, venda e dificuldades encontradas durante a safra. 


\section{Resultados e Discussão}

O instrumento de coleta de dados foi online e presencial, totalizando 4 questionários, compostos entre 10 a 20 questões cada, com participação de 30 produtores, localizados na Região dos Campos Gerais, no estado do Paraná. As questões eram em sua maioria de múltipla escolha, mas havendo também descritivas. O intuito desta pesquisa foi acompanhar através de planilhas e gráficos a estrutura familiar, os principais métodos de produção, cultivo de tratos culturais dos produtores de tabaco na Região dos Campos Gerais. O período de coleta de dados ocorreu em 4 momentos, sendo no período de produção de mudas, no plantio e durante o cultivo na safra 2020/2021.

\subsection{Produção de mudas}

No primeiro questionário, foi possível analisar o perfil do produtor, como a composição familiar e gênero presente na safra de produção, idade, período de plantio, fonte de renda, variedade cultivada, solo, análise do solo, época de semeadura, tipos de substrato e bandeja, doença e pragas, e valor de compra e produção.

Pode-se notar a grande variação da composição das famílias, onde há famílias compostas por mais pessoas e também outras que estão se iniciando. E também a integração gradual da mulher no campo, que ao passar dos anos conquista aos poucos seu espaço no meio agrícola, mesmo não um número tão relevante (Figura 1).

Figura 1 - Dados referente à Composição familiar e Gêneros presentes na área onde produz. Fonte: Leticia Horst.
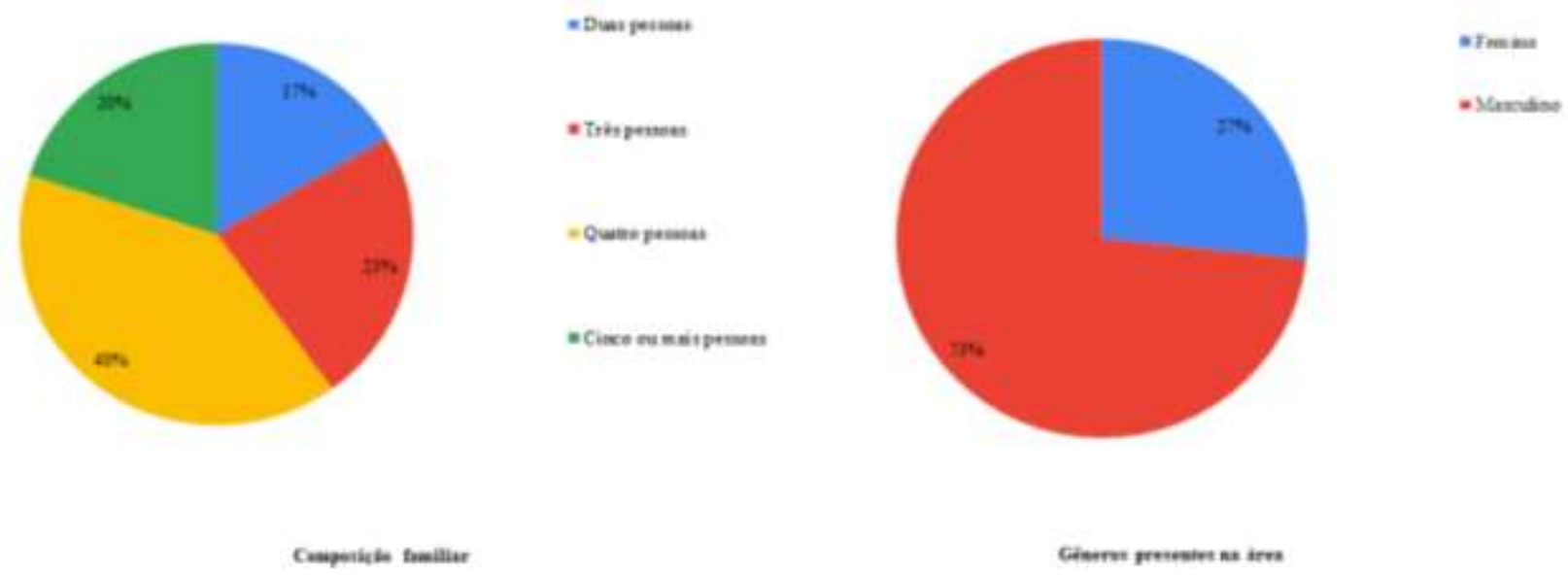

Fonte: Autores.

A idade dos participantes é em sua maioria a partir dos 25 anos, percebendo uma queda de chegada de novos produtores, e a permanência dos produtores por longos períodos de produção (Figura 2). Podendo concluir até o presente momento, que os produtores são em sua maioria homens, com uma experiência significativa na produção. 
Figura 2 - Dados referente a Idade do(a) produtor(a) e o Período de plantio de tabaco. Fonte: Leticia Horst.

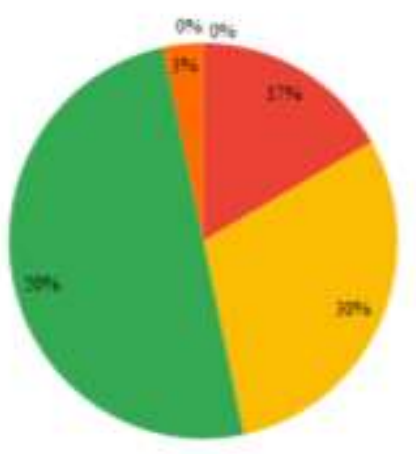

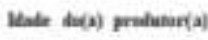
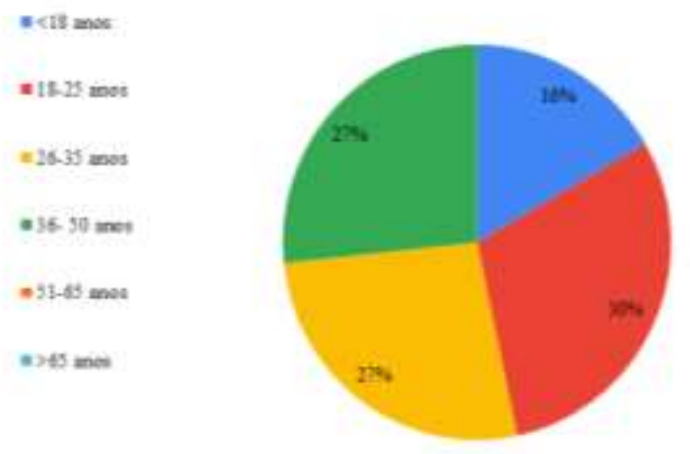

$5<5$ ans

a.15 arse

$=11-30$ anas

11-2t mes

Fonte: Autores.

Uma boa alternativa de produção em pequenas propriedades é o tabaco. Pois como se trata de uma mão-de-obra manual em grande parte da safra, possui um bom retorno financeiro, produção relativamente simples e de baixo custo, os produtores a tornam sua principal fonte de renda (Figura 3).

Figura 3 - Dados referente a porcentagem de ação do tabaco como principal fonte de renda do agricultor. Fonte:

Leticia Horst.

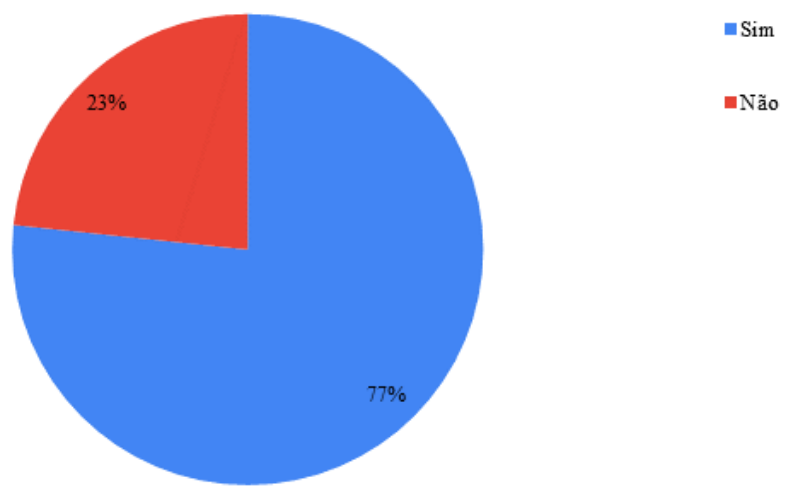

Principal fonte de renda

Fonte: Autores.

Dentre as variedades cultivadas (Virginia, Burley, MaryLand, Black e Comum) as mais comumente cultivadas na Região dos Campos Gerais são: Virginia, Burley e MaryLand. A variedade Virgínia, também conhecida popularmente como 
fumo de estufa, é a mais cultivada na região (Figura 4). O tipo de solo no qual abrange maior quantidade de produtores é o é o Argiloso, entre as outras também citadas em memória, como: siltoso e arenoso (Figura 4).

Figura 4 - Dados referente a variedades cultivadas na Região dos Campos Gerais e o tipo de solo mais utilizado em sua produção. Fonte: Letícia Horst.
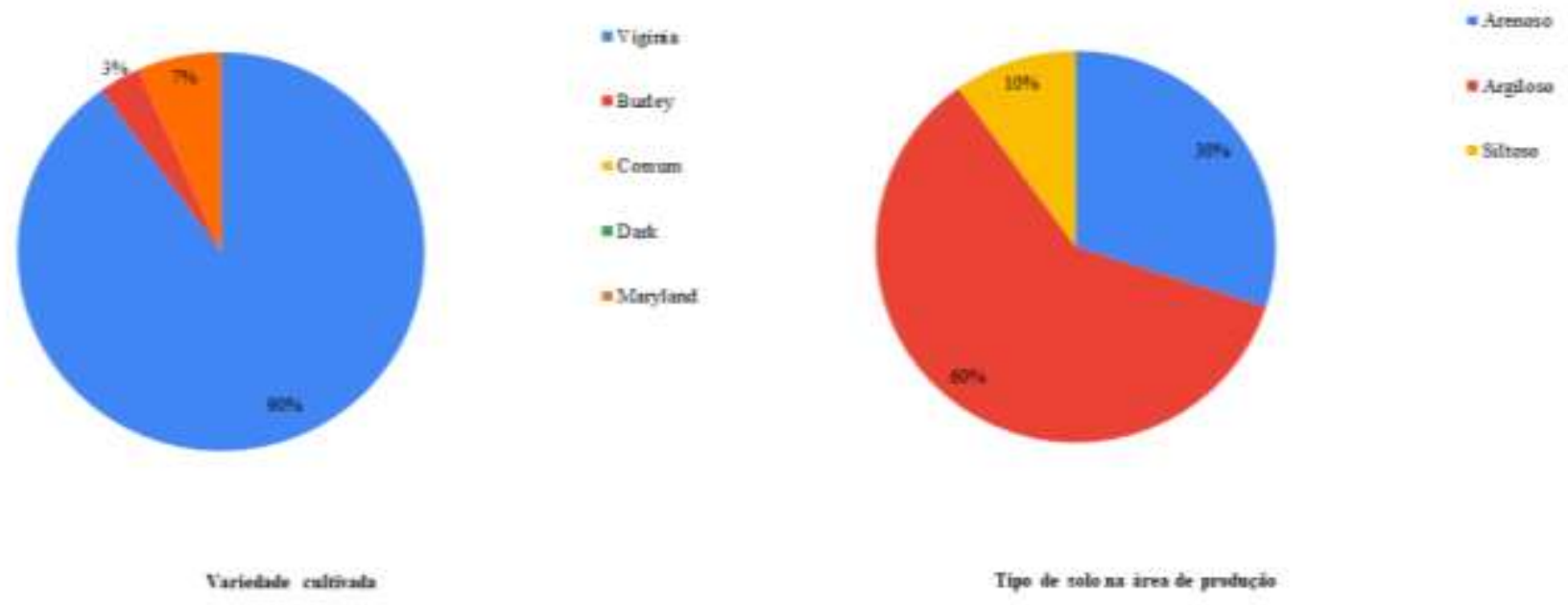

Fonte: Autores.

A fim de garantir uma boa produtividade é importante cuidar dos atributos químicos, físicos e biológicos do solo, e para que sejam aplicados métodos corretos de correção e adubação do solo é necessário a realização de análise física e química. Referente a pesquisa realizada, a frequência com que os produtores realizam a análise de solo é em sua maioria frequente (a cada 1 - 2 anos), havendo aqueles que realizam com menos frequência e uma pequena porcentagem que realiza a atividade (Figura 5).

O início da safra se dá com a semeadura das sementes, havendo uma variedade entre os meses de maio, junho e julho. A variação dos meses ocorre devido ao planejamento do produtor, que varia em relação a meteorologia, pretensão de fim de safra, variedade, ou até mesmo por escolha do produtor (tradição). Os meses mais comuns de realizar o plantio são junho e julho (Figura 5), havendo em sua minoria semeaduras que ocorrem no final do mês de maio. 
Figura 5 - Dados referente a frequência que os produtores realizam análise de solo em sua propriedade e a época de semeadura. Fonte: Leticia Horst.

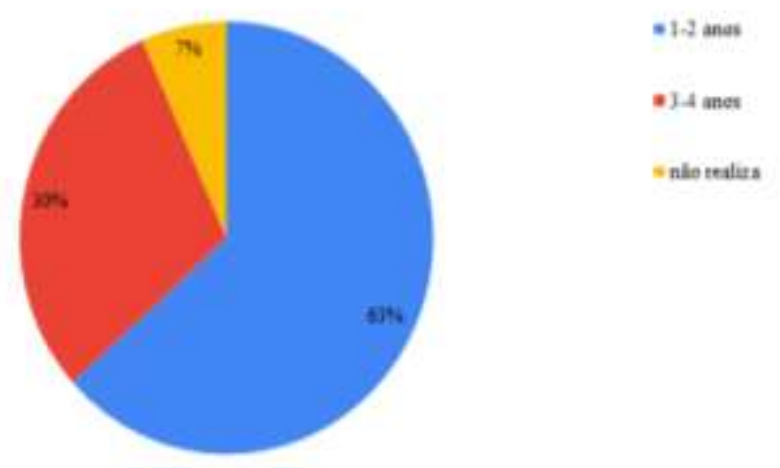

Trequència na realizacie de asaline de salt

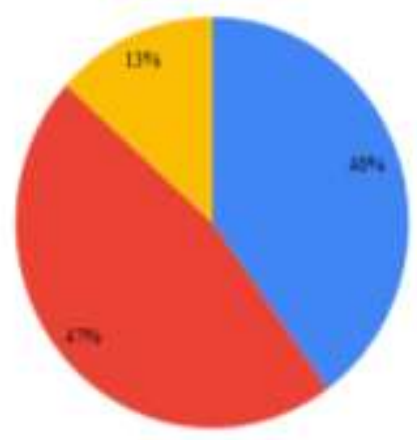

Ipaca de semeadurs
* Junta

* fultw

s.min

Fonte: Autores.

No sistema de produção de mudas estilo Float, são utilizadas piscinas de plástico com bandejas, que são preenchidas com substrato. Existem inúmeros tipo de substrato no mercado, e por muito tempo o mais utilizado foi a de casca de pinus, o que pode mudar com o passar dos anos com a chegada do substrato com fibra de côco (Figura 6). Já em relação às bandejas, por um bom tempo havia apenas aquelas cujo material é de isopor, mas com a chegada de bandejas de plástico, a preferência do produtor está mudando gradualmente para o novo modelo (Figura 6).

Figura 6 - Dados referentes ao tipo de substrato e bandeja utilizado pelos produtores. Fonte: Leticia Horst.
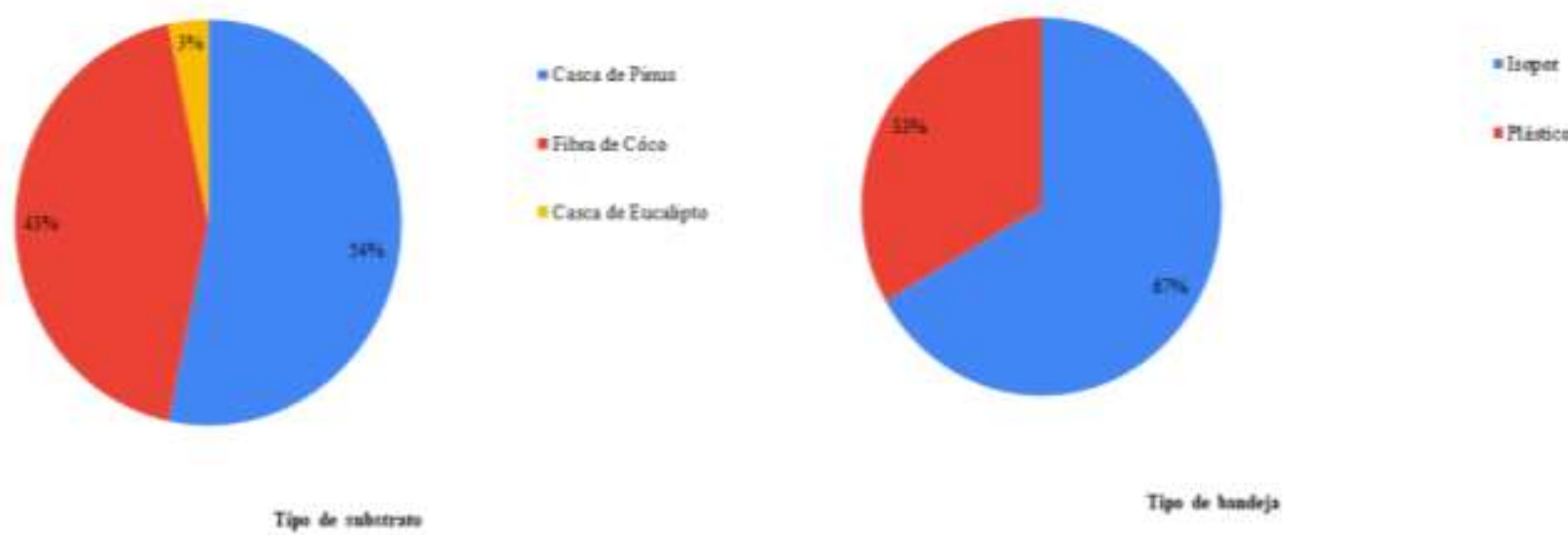

Fonte: Autores. 
Durante a produção de mudas, o ambiente se torna susceptível a algumas pragas e doenças, sendo as mais comuns conforme os produtores a mosca branca (Bemisia tabaci), lesmas (Vaginula spp.), Mofo azul (Peronosora tabacina) e Mela (Pythuim spp.). Com a conscientização dos produtores essas doenças estão sendo mais controladas, com a escolha de substrato, troca de bandeja, higienização, e sementes tratadas (Figura 7).

Figura 7 - Dados referente a doenças e pragas na produção de mudas. Fonte: Letícia Horst.

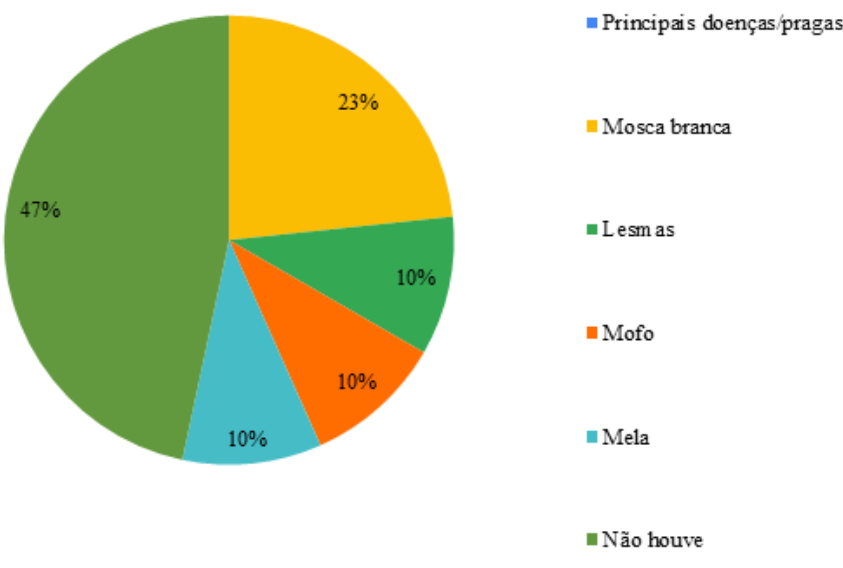

Principais doenças/pragas

Fonte: Autores.

O planejamento é uma atividade extremamente importante, pois pode influenciar totalmente no lucro do produtor. Pois muitas vezes a falta de planejamento pode fazer que ocorram gastos desnecessários. Como por exemplo, o valor médio na compra de mudas chega a ser $200 \%$ maior que o preço de produção (Figura 8), o que é um caso comum, que muitas vezes passa despercebido pelo produtor, mas é um gasto que pode ser evitado com planejamento adequado.

Figura 8 - Dados referente a preço médio de compra e de produção de mudas. Fonte: Leticia Horst.
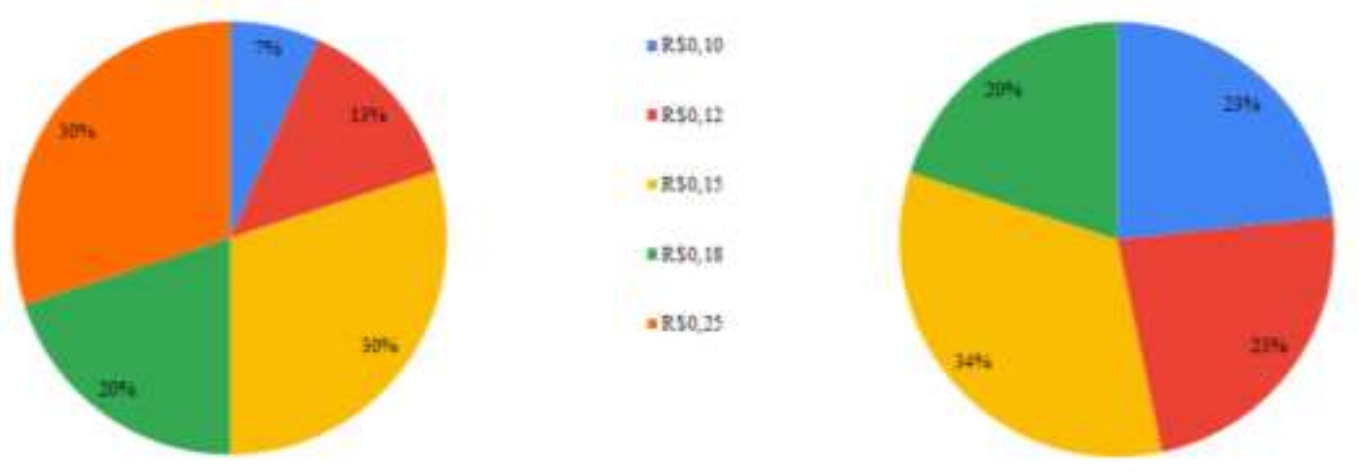


\subsection{Plantio}

No segundo questionário, foi possível analisar a realidade do produtor com a preparação do solo para o replantio das mudas, a adubação que é realizada, a quantidade de mudas utilizadas, a situação das mudas e a época que realizam a atividade. Havendo questões onde os produtores expuseram sua opinião sobre os assuntos abordados.

Pode-se notar um nítido padrão quando abordado a questão do preparo do solo nas áreas cultivadas. Onde ao final da safra, é passado a grande aradora e niveladora, afim de revolver o solo onde estão os caules restantes da produção e por fim nivelar o solo. Em seguida, para fins lucrativos, é realizada semeadura de feijão ou milho, sendo realizado um ciclo cultural entre essas culturas e o tabaco. E por fim para aqueles que realizam um sistema de plantio direto (Figura 9), as culturas mais utilizadas são o milheto, o centeio e a aveia.

Figura 9 - Dados referente ao sistema de plantio realizado na área de cultivo. Fonte: Leticia Horst.

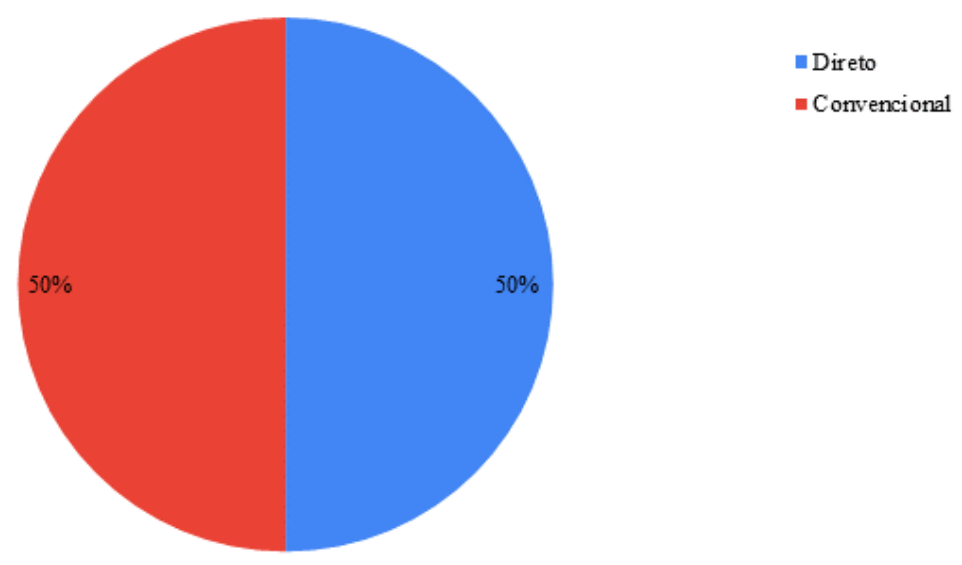

Sistema de plantio

Fonte: Autores.

Para a finalização do preparo do solo, alguns produtores realizam a formação de camalhões e junto deles já aplicam adubo, outros aplicam adubo de forma mais manual, com regadores. E após o replantio é variada de uma a duas adubações, onde são aplicadas de maneira manual pé por pé. Havendo uma variação de uma a três aplicações de adubo entre os produtores (Figura $10)$. 
Figura 10 - Dados referente a quantidade de vezes que é realizada adubação na área de cultivo. Fonte: Leticia Horst.

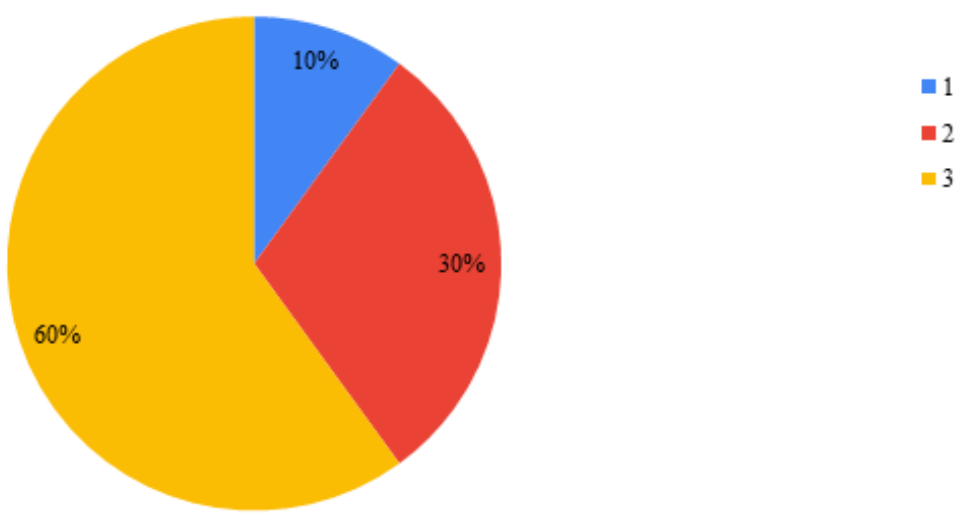

Quantidade de vezes é realizada a adubação

Fonte: Autores.

A dosagem correta do adubo não é muito estudada pelos produtores, onde eles muitas vezes apenas dividem a quantidade de adubo que compram para toda a área de maneira igual. Por exemplo, "aplico um saco de $50 \mathrm{~kg}$ para 1.000 pés", havendo uma variação de até 18 gramas entre as respostas dos produtores.

As mudas preparadas para o plantio são podadas, para que seu caule seja mais resistente às condições climáticas, como os ventos e chuvas, que são fatores que não ocorriam durante a época que eram abrigadas nos canteiros. A quantidade de podas na maioria das propriedades é realizada quatro vezes, mas havendo variações de até duas podas (Figura 11).

Figura 11 - Dados referentes a quantidade de podas realizadas nas mudas para o replantio nas propriedades. Fonte: Leticia Horst.

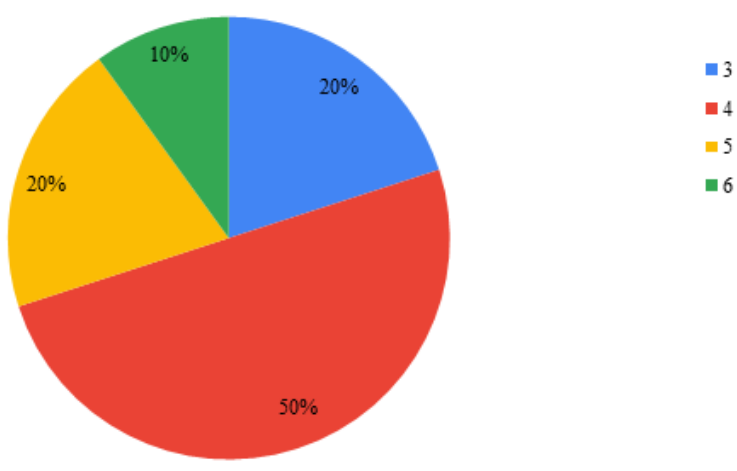

Quantidade de podas

Fonte: Autores.

A quantidade de mudas varia pouco, entre 15.000 e 17.000 pés/ha (Figura 12), essa variação pode ocorrer conforme a variedade cultivada e também a quantidade de estradas de passagem existentes na área. Já a época de plantio é determinada muitas vezes após o período de chuvas, devido a umidade do solo presente. Não havendo mais geadas, nem temperaturas muito 
elevadas, fatores que podem influenciar no desenvolvimento da planta. Os meses mais favoráveis são setembro e outubro (Figura 12).

Figura 12 - Dados referentes a época de plantio e a quantidade média de mudas/ha. Fonte: Leticia Horst.
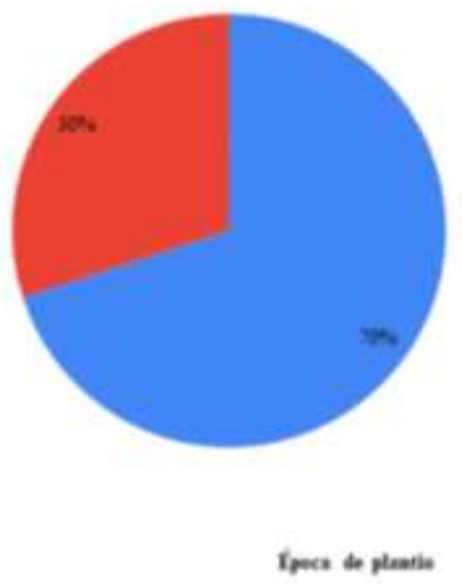

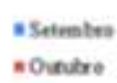

oveutre

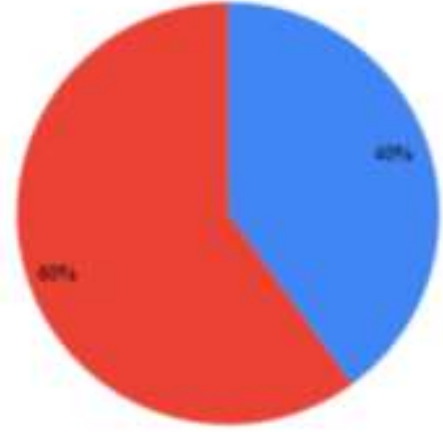

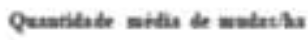

$=12,000$

$* 17,000$

Fonte: Autores.

\subsection{Cultivo}

No terceiro questionário aplicado, notou-se resultados referente à mão-de-obra, principais doenças e pragas após o plantio, defensivos químicos, tratos culturais e conhecimento da cultura. Com isso, foi possível caracterizar com mais detalhes os produtores da localidade dos Campos Gerais.

A mão-de-obra terceirizada é bastante utilizada principalmente em épocas de colheita, porém ainda é muito usual os produtores realizarem uma cooperação mútua entre si, com trocas de dia de serviço, reduzindo os custos. A dificuldade e a desvalorização do serviço ainda fazem com que haja uma baixa demanda desse tipo de mão-de-obra e um valor comumente não tão elevado (Figura 13).

Figura 13 - Dados referente a utilização e valor da mão-de-obra terceirizada. Fonte: Leticia Horst.

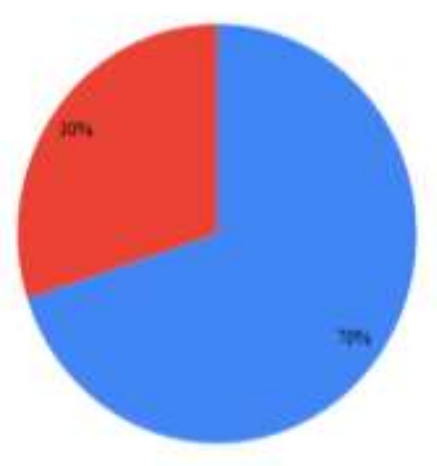

trilimasie de mio-otraterceirtusts

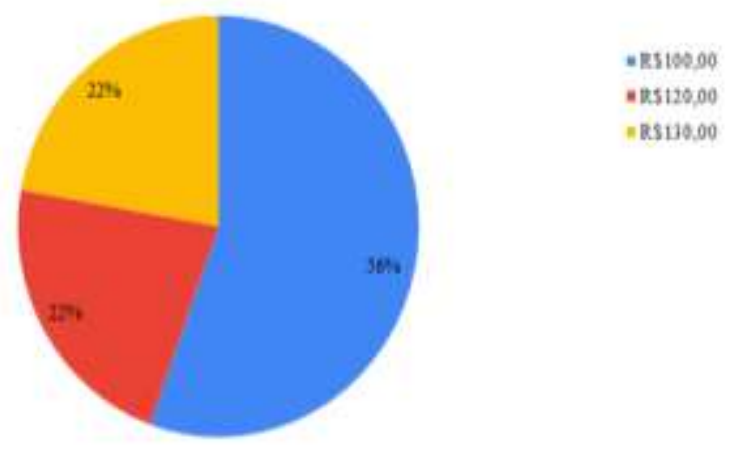

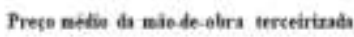

Fonte: Autores. 
Durante o desenvolvimento na lavoura, foram observados as principais doenças e pragas: murcha bacteriana, pulgão preto, lagarta, verme arame e talo oco. Sendo o pulgão preto a principal praga que ataca a cultura (Figura 14). Utilizando como maneira de controle de pragas e doenças o manejo preventivo em maior quantidade (Figura 14). Observou também a dificuldade do produtor referente ao conhecimento sobre os defensivos agrícolas (Figura 15).

Figura 14 - Dados referente às principais pragas e doenças encontrados na cultura e o tipo de manejo utilizado para o controle das mesmas. Fonte: Leticia Horst.

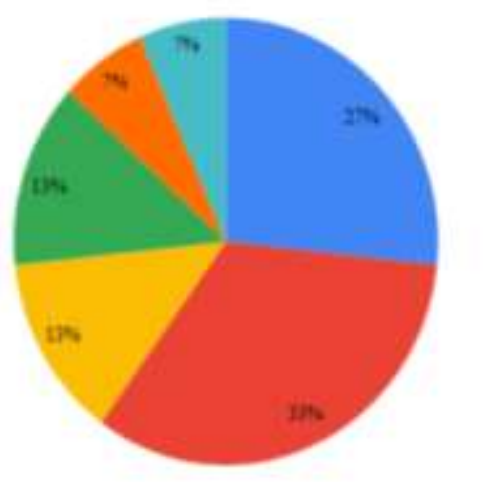

Manipais haseses oprot

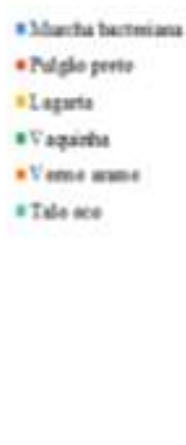

- Noleperene

These

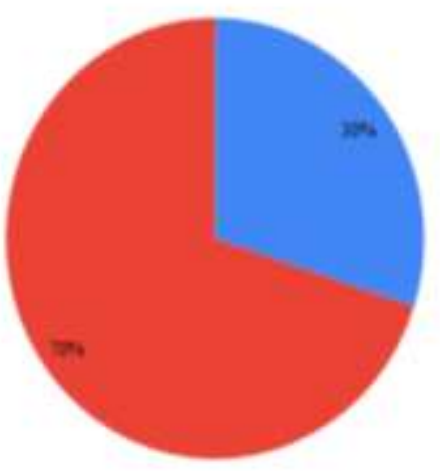

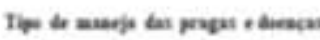

Fonte: Autores.

Figura 15 - Dados referentes ao conhecimento dos produtores sobre agrotóxicos. Fonte: Leticia Horst.

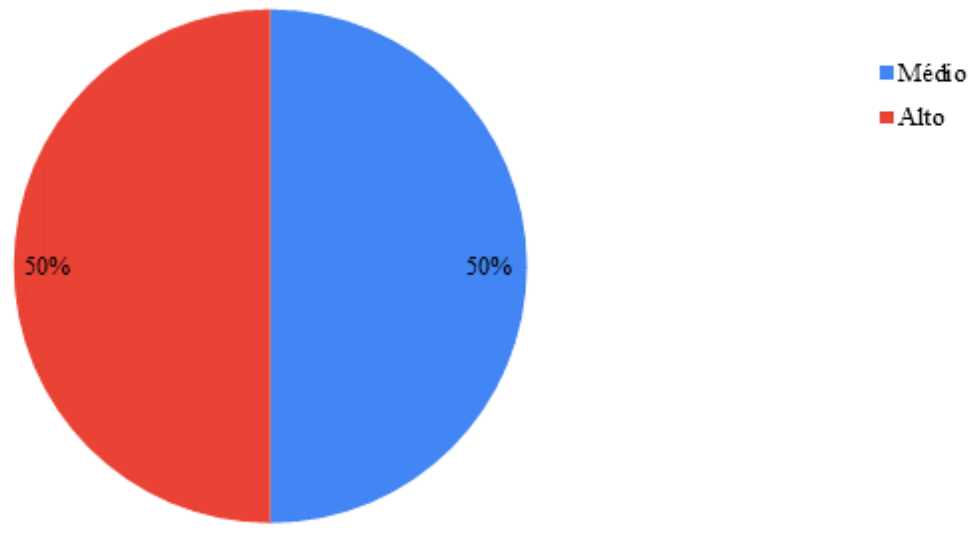

Conhecimento referente a agrotóxicos

Fonte: Autores.

E por fim, o conhecimento do produtor em relação a cultura, a realização de cursos que aprimoram o seu conhecimento (Figura 16), e também a utilização de outros meios de conhecimento, como a internet, revistas, livros e aplicativos (Figura 16. Ambos obtendo resultados que podem ser melhorados, e consequentemente melhorar a produção do tabaco, com produtos e serviços de maior qualidade. 
Figura 16 - Dados referente a quantidade de produtores que realizaram cursos referente a produção e de produtores que utilizam meios que auxiliam na produção. Fonte: Leticia Horst.
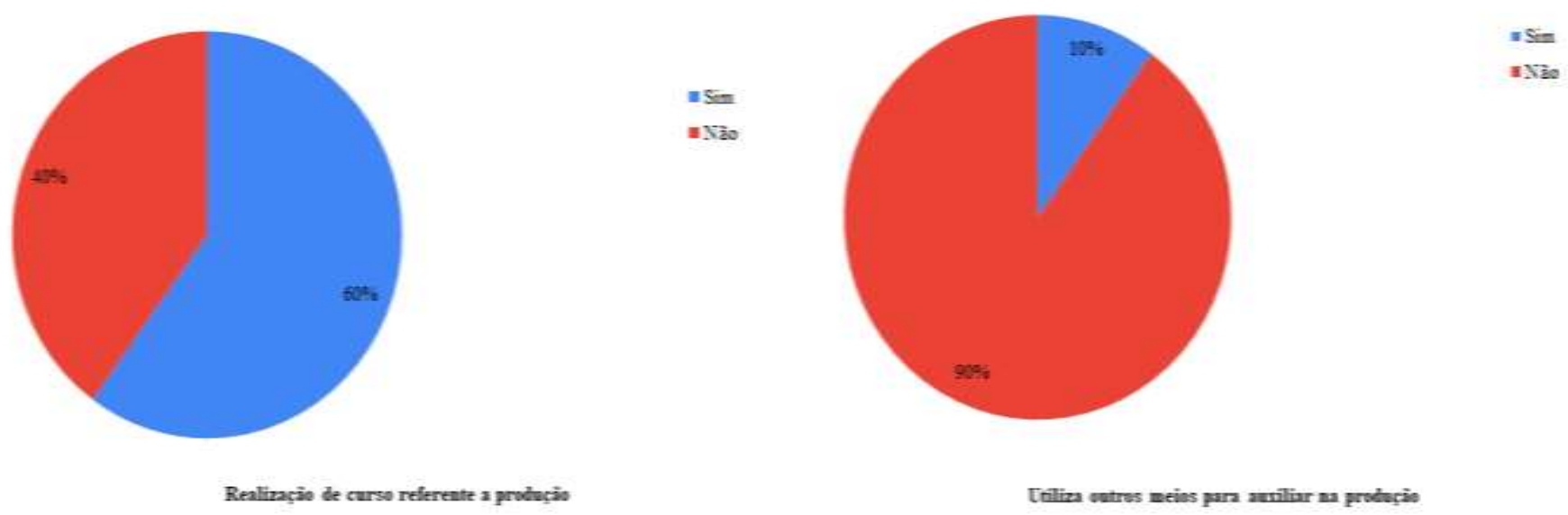

Fonte: Autores.

\subsection{Colheita, secagem e venda}

No quarto e último questionário compartilhado para os produtores, notou-se resultados em relação à época de colheita, ponto, período, mão-de-obra em relação à colheita. Secagem das folhas, utilização de lenha, classificação das folhas, vendas, dificuldades durante a colheita e principal mão-de-obra utilizada durante toda a safra.

As colheitas dão início aos meados do mês de novembro e início de dezembro, entre os entrevistados $80 \%$ iniciam a colheita em dezembro (Figura 17). E o ponto de colheita é definido por uma menor porcentagem (Figura 17) referente a época de plantio (e desbrota). O que seria inadequado, sabendo-se que o correto é através da coloração amarelada da folha, que retrata a maturação, garantindo a qualidade final do produto para a venda.

Figura 17 - Dados referente a época de colheita e ponto de colheita. Fonte: Leticia Horst.

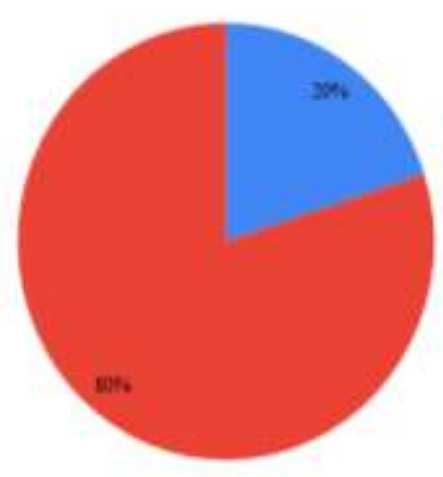

Im que epeca se deu inicio as colheitas?
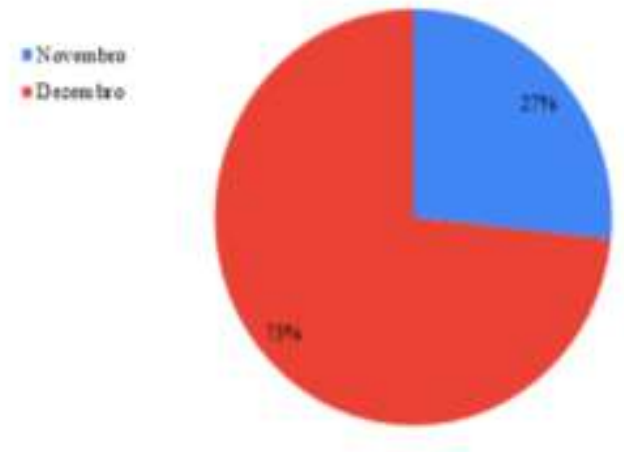

Cans o befinite s panis de collirita?
- Cortarma o peniods apda planis

- Certama

coloriçio manne io

Fonte: Autores. 
Em relação ao período que se estende às colheitas, há uma variação em relação à variedade da planta. Em variedades tipo Virgínia este período tem duração de 2 e 3 meses em uma média (Figura 18), já nas variedades de Burley e MaryLand esse período tem uma média de 20 dias (Figura 18), já que a colheita é realizada em uma única vez. E a principal mão-de-obra utilizada nesta fase é a terceirizada (Figura 18), e em menor quantidade, mas utilizada, que é a familiar. Porém, na safra em geral a mãode-obra mais utilizada é a familiar, ou uma integração entre ela e a terceirizada (Figura 19), pois a mão-de-obra terceirizada é mais utilizada em fases que necessitam de mais pessoas como por exemplo a colheita e o plantio.

Figura 18 - Dados referentes ao período de colheita e mão-de-obra utilizada na fase. Fonte: Leticia Horst.
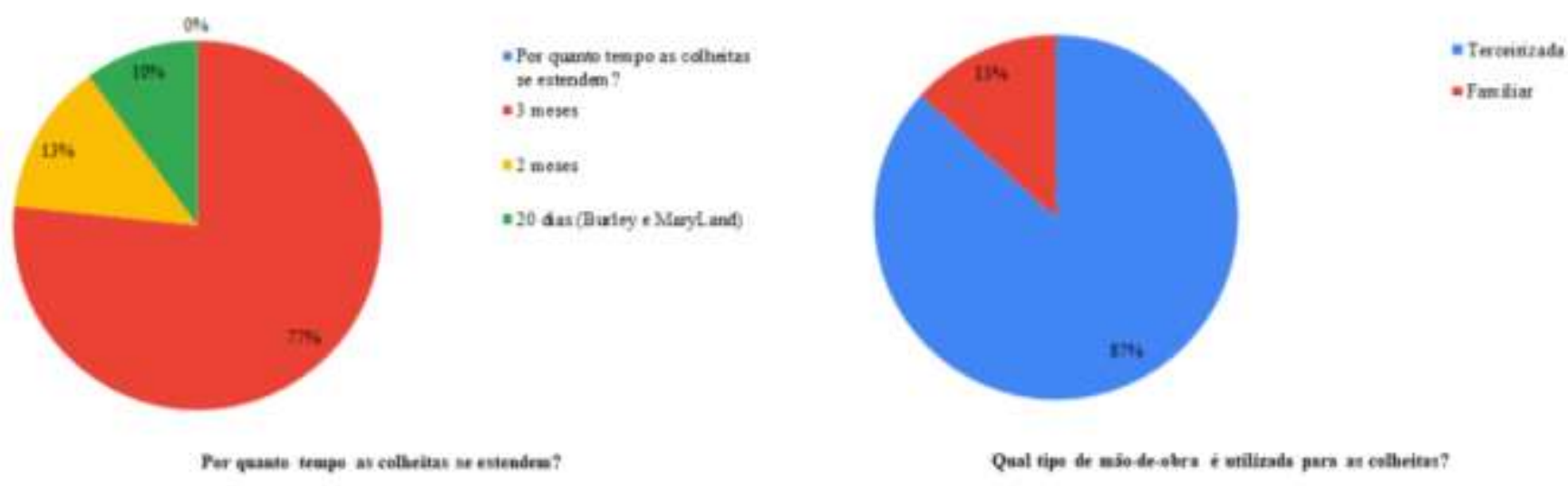

Fonte: Autores.

Figura 19 - Dados referentes à principal mão-de-obra utilizada na safra. Fonte: Leticia Horst.

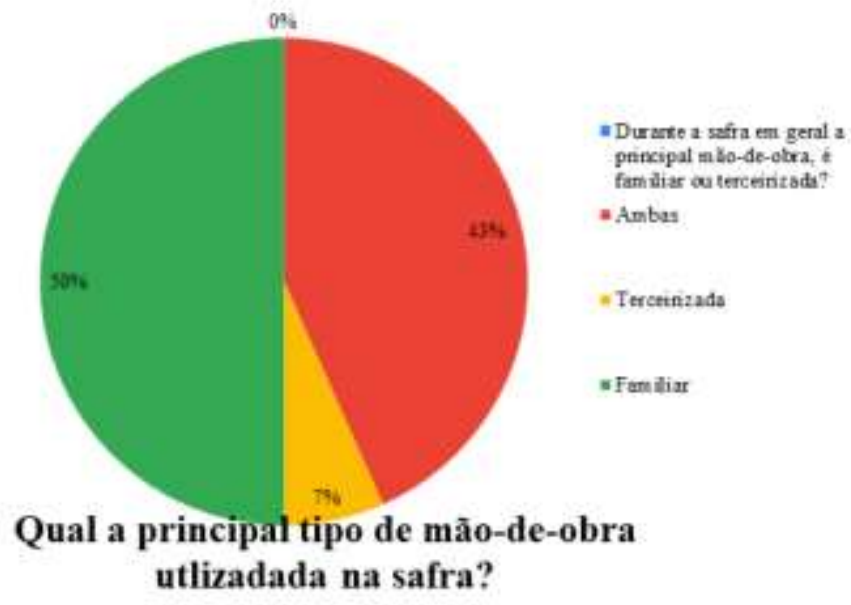

Fonte: Autores.

Para a cura/secagem das folhas há duas formas: "artificial” (com circulação forçada de ar quente, ou seja, estufas) e outra natural (galpões). Essa variação ocorre de acordo com a variedade do tabaco, em sua maioria a variedade Virgínia, onde sua secagem é realizada em estufa (Figura 20), e as variedades Burley e MaryLand em galpões. Aqueles secados em estufa as folhas são soltas (Figura 20) e em galpões elas são amarradas em um cabo de madeira. 
Figura 20 - Dados referentes à estrutura utilizada e a forma de secagem das folhas colhidas. Fonte: Leticia Horst.

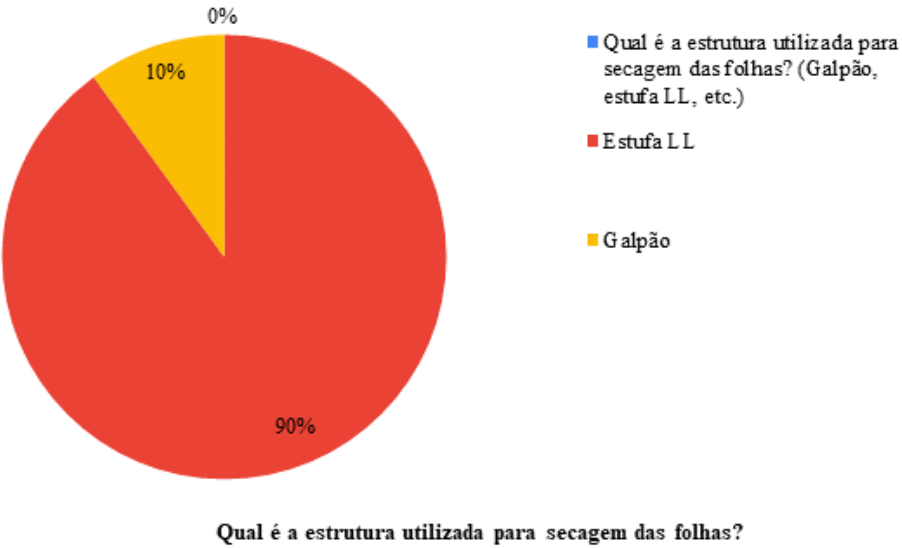

Fonte: Autores.

A secagem realizada em estufas, o ar quente que circula na estrutura tem origem de uma fornalha, onde é necessária a queima de madeira. A quantidade varia de 4 a 7 metros de lenha por secagem/colheita (Figura 21) e o preço médio por metro é de R\$60,00 (Figura 21), havendo variações.

Figura 21 - Dados referente a quantidade de lenha utilizada na fornalha e o preço médio por metros da lenha. Fonte: Leticia Horst.
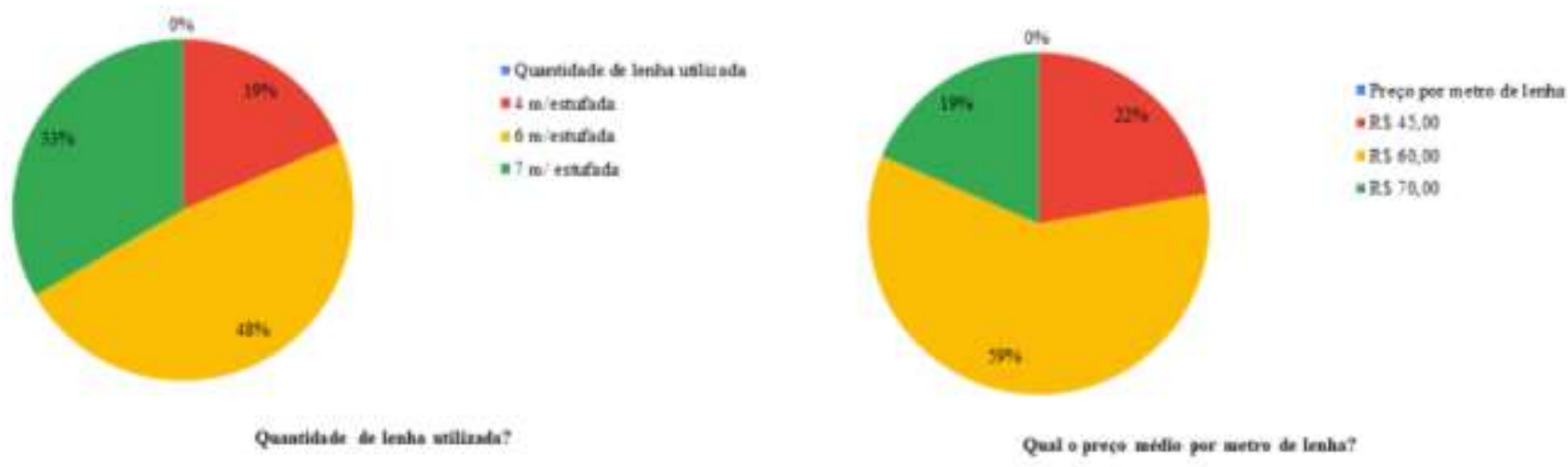

Fonte: Autores.

No geral, a classificação das folhas é uma etapa simples, onde é separada por coloração (Figura 22), mas também a espessura da folha, que é realizada pelo tato. Durante toda a fase de desenvolvimento final da planta e colheita a maioria dos produtores se depararam com problemas (Figura 22), ou situações que não foram planejadas, sendo elas: meteorológicas (exemplo: falta de chuvas e granizo), pragas (exemplo: pulgões) e doenças (exemplo: murcha bacteriana). 
Figura 22 - Dados referentes a classificação de folhas e de problemas durante essa etapa da safra. Fonte: Leticia Horst.

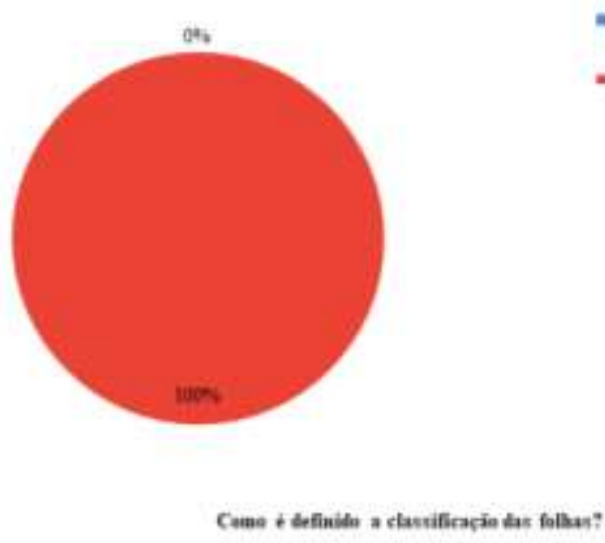

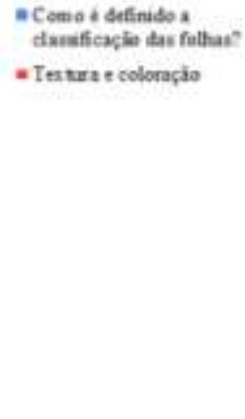

dausficapie tas fultus

Textura e coloraçă.

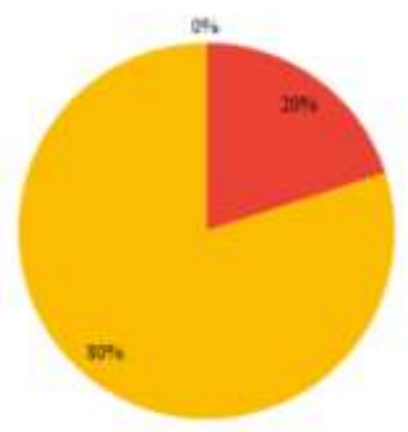

Wh, eisitirim pollemas relacionades a diala, doenças ou parar

- Nàn

Fonte: Autores.

A venda do tabaco é um ponto que é extremamente desfavorecido, que não agrada os produtores em geral (Figura 23). Cada vez mais a mão-de-obra, a comercialização, a presença de pragas e doenças e os fatores meteorológicos, fazem a produção se tornar mais dificultosa na opinião dos produtores. Os principais desagrados estão presentes na mão-de-obra (Figura 23), que se torna cada vez mais cara e de difícil acesso.

Figura 23 - Dados referentes à satisfação de venda do tabaco e as dificuldades encontradas durante a safra. Fonte: Leticia Horst.

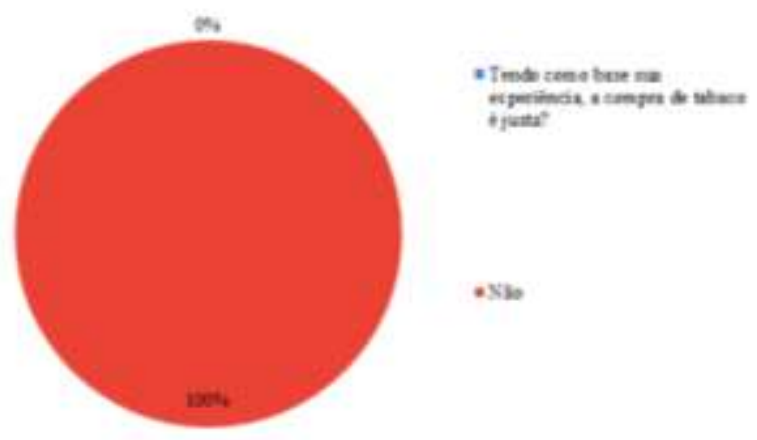

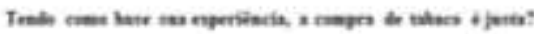

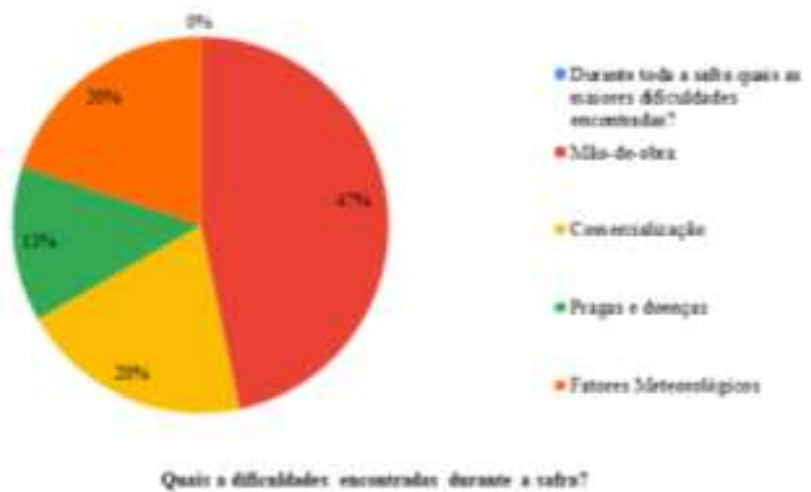

Fonte: Autores.

Este trabalho, com caráter descritivo, trouxe informações mais detalhadas sobre a composição familiar dos fumicultores na região do Campos Gerais, assim como detalhes da produção de mudas, sistema de plantio e cultivo, manejo da cultura, forma de colheita, secagem e venda. Há muita escassez dessas informações na literatura em relação a cultura do tabaco, sendo este trabalho pioneiro na região estudada. Com o levantamento deste questionário, percebe-se a falta de informações e orientações técnicas durante o crescimento e desenvolvimento da cultura dentro da propriedade.

Brum et al. (2020), realizou um levantamento similar a este no Rio Grande do Sul, onde os autores citam que os agricultores entrevistados em sua pesquisa também relataram que, por vezes, se veem explorados e endividados junto às empresas do setor, causando dependência e subordinação dos trabalhadores. Do lado das empresas, isso acontece com a má classificação 
do fumo após a saída da lavoura, o que resulta em preços mais baixos pagos pelo produto na porta das empresas fumageiras. Do lado do agricultor, a busca pela vantagem acontece quando o preço pago pelas firmas concorrentes, ou por intermediários, são superiores ao que a empresa com quem possui contrato estaria pagando. As vezes ocorre dos produtores venderem o seu produto para as empresas concorrentes, em detrimento daquelas que eles têm contrato.

Enfim, o estudo permite destacar ainda, em conclusão, que a relação entre os agentes de produção está estabelecida através de contratos e do Sistema Integrado de Produção (SIPT); que o Rio Grande do Sul é o principal produtor de fumo no Brasil; que o contrato firmado entre empresas compradoras e produtores gera uma situação de dependência destes últimos, pois os impossibilita de praticar outras formas de produção e comercialização; e que o mercado do tabaco no Brasil é dominado por poucas empresas, com predominância do capital estrangeiro (Brum et al., 2020).

\section{Considerações Finais}

Contudo, pode-se notar que na produção do tabaco na Região dos Campos Gerais, nas propriedades o gênero em maior quantidade é o masculino com uma idade média de trinta anos. Estando presente no cultivo a mais de dez anos, sendo sua principal fonte de renda. Utilizando manejos que estão sendo ultrapassados, gerando maior incidência de pragas e doenças e apresentando dificuldades principalmente na adubação e manejo adequado ao solo, a falta de atenção e conhecimento com fatores que podem influenciar a produtividade e lucro final de produção. Havendo uma insatisfação dos produtores em relação a comercialização do produto, referente uma desvalorização na compra, e com preços, que não sofrem grandes alterações mesmo com a alta do dólar nos momentos atuais.

\section{Referências}

Afubra. 2020. Afubra - Associação dos Fumicultores do Brasil. <https://afubra.com.br/fumicultura-brasil.html>.

Boeira, S. L. 2006. Indústria de tabaco e cidadania: confronto entre redes organizacionais. Revista de Administração de Empresas, v. 46, n. 3, p. 28-41.

Brum, A. L. et al. 2020. Cadeia produtiva do tabaco na Região Sul do Brasil: estudo da composição e do relacionamento dos seus agentes. Research, Society and Development, v. 9, n. 9, p. e852997769.

Riquinho, D. L. \& Hennington, E. A. (2016). Sistema integrado de produção do tabaco: saúde, trabalho e condições de vida de trabalhadores rurais no Sul do Brasil. Cad. Saúde Pública, 32 (12).

Rosa, M. P. 2018. Os sentidos do trabalho camponês na produção do tabaco e na agroecologia: possibilidades de transformação e resistência. Mestrado em Psicologia Social-São Paulo: Universidade de São Paulo.

Silveira, R. L. L. Da. 2015. A cultura do tabaco na Região Sul do Brasil: dinâmica de produção, organização espacial e características socioeconômicas. Geografia Ensino \& Pesquisa. v. 19, n. 2.

Klettenberg,R. Z. 2019. O produtor integrado de tabaco. O conhecimento aplicado para o crescimento da propriedade, p.5.

Salvadego, M. 2019. O produtor integrado de tabaco. Uma nova tragetória construída através de pareceria ,p. 10-11. 